\title{
DETEKSI KHIMAR WANITA PADA CITRA WAJAH MENGGUNAKAN METODE GAUSSIAN MIXTURE MODEL
}

\author{
Abdul Jahir ${ }^{1}$, Kuat Indartono ${ }^{2}$ \\ 1,2 STMIK AMIKOM Purwokerto \\ Jl. Pol Soemarto,Karang jambu Purwanegara, Kec. Purwokerto Utara \\ Kabupaten Banyumas - Jawa Tengah 53127 Tlp.(0281) 623321 \\ Email : abduljahir@amikompurwokerto.ac.id ${ }^{1)}$, indartono@amikompurwokerto.ac.id ${ }^{2)}$
}

\begin{abstract}
Indonesia, is a predominantly Islamic nation. In Islam has been set especially for Muslim women there is an obligation to cover aurat. Closing the nakedness can be done by wearing a hijab to avoid sin and all possible ugliness. Many cases of mistreatment of women who indulge in nurse, so this will affect the psychological of men. The face is one of the aurat that must be covered. Closing the face area can be done using a veil or khimar. But in reality there are still many Muslim women who have not wearing khimar, even found many pictures that indulgence aurat. Detection of aurat based on the face image is a new breakthrough in efforts to glorify Muslim women. In this study developed a method to detect women's aurat by extracting the skin features then check the difference of skin with khimar. The methods used are Viola-Jones face detection, GMM (Gaussian Mixture Model), and Roberts edge detection. The results of the aurat detection showed an accuracy of $95 \%$ based on a frontal facial khimar image.
\end{abstract}

Keywords-Aurat detection, Viola-Jones, Gaussian Mixture Model, Roberts edge detection

\begin{abstract}
ABSTRAK
Indonesia, merupakan negara mayoritas beragama islam. Dalam islam telah mengatur khususnya bagi wanita muslim ada kewajiban untuk menutup aurat. Menutup aurat dapat dilakukan dengan mengenakan hijab agar terhindar dari dosa dan segala keburukan yang mungkin dapat terjadi. Banyak terjadi kasus penganiayaan terhadap wanita yang mengumbar auratnya, sehingga hal ini akan mempengaruhi psikologis lakilaki. Wajah merupakan salah satu aurat yang harus ditutupi. Penutupan area wajah dapat dilakukan dengan menggunakan jilbab atau khimar. Namun pada kenyataannya masih banyak wanita muslim yang belum mengenakan khimar, bahkan banyak ditemukan gambar-gambar yang mengumbar aurat. Deteksi aurat berdasarkan citra wajah merupakan suatu terobosan baru dalam upaya memuliakan wanita muslim. Dalam penelitian ini dikembangkan suatu metode untuk mendeteksi aurat khusus area wajah wanita dengan mengekstrak fitur kulit kemudian memeriksa perbedaan kulit dengan khimar. Metode yang digunakan adalah deteksi wajah Viola-Jones, GMM (Gaussian Mixture Model), dan deteksi tepi Roberts. Hasil deteksi aurat menunjukkan akurasi 95\% berdasarkan gambar wajah khimar yang diambil secara frontal.
\end{abstract}

Kata Kunci-Deteksi aurat, Viola-Jones, Gaussian Mixture Model, deteksi tepi Roberts 


\section{Pendahuluan}

Dewasa ini perkembangan media sosial sangatlah pesat dan penggunaan media sosial telah semakin luas dengan intensitas yang tinggi diantara pemakainya. Teknologi media sosial saat ini memiliki berbagai bentuk seperti misalnya majalah digital, forum internet, weblog, blog sosial, jejaring sosial, foto atau gambar, dan video. Manfaat penggunaan media social sangatlah terasa, namun juga dapat berdampak buruk. Salah satu sisi buruk media sosial diantaranya seseorang dengan mudah berbagi foto/gambar ke pengguna lain dengan berbagai aktivitas yang dilakukannya dengan tidak memperhatikan foto/gambar tersebut telah menutup aurat atau belum. Bagi wanita muslim ada kewajiban untuk menutup aurat. Masalah kekerasan berpeluang terjadi jika aturan agama tersebut tidak dilaksanakan. Mengumbar aurat salah satu pornografi yang berdampak terhadap psikologi manusia sehingga dapat mengakibatkan suatu bentuk kekerasan atau kriminalisasi terhadap kaum wanita [1]. Manfaat yang didapat jika seorang wanita yang menutupi khimar akan relatif lebih aman dari tindak kekerasan.

Computer vision merupakan ilmu yang mencakup dasar pengolahan citra hingga analisis dan pemanfaatan informasi yang terdapat pada suatu gambar untuk tujuan tertentu [2]. Data yang diolah pada citra akan menghasilkan informasi berupa angka dan simbol yang dapat diberdayakan dengan menggunakan sistem berbasis mesin cerdas [3]. Bidang kajian computer vision juga memiliki kemampuan penglihatan dalam mengamati, menganasis, memahami, dan memutuskan [4]. Pemahaman informasi ini tidak luput dari proses penguraian datadata dengan bantuan geometri, statistik dan teori pembelajaran mesin [5]. Banyak penerapan Computer Vision yang diprogram untuk memecahkan masalah tertentu dengan berbagai metode. Beberapa penelitian yang telah dilakukan dalam mengidentifikasi bagian tubuh manusia khususnya untuk mendeteksi wajah [6][7][8][9], dan deteksi kulit seperti pada penelitian [10][11] $[12][13][14][15][16]$.

Dalam penelitian ini, untuk mendeteksi aurat pada sebuah gambar/foto digunakan tahapan pra pengolahan deteksi wajah dan kulit. Algoritme deteksi wajah yang dikembangkan oleh Viola-Jones merupakan metode yang biasa digunakan sebagai pengenalan wajah dan memiliki akurasi dan kecepatan yang sangat baik [16]. Sedangkan klasifikasi deteksi kulit dengan metode GMM sangat ringan 
sehingga dapat digunakan untuk proses komputasi real-time [17] serta komputasinya yang cepat untuk data beresolusi tinggi [18]. Deteksi aurat belum pernah dilakukan sebelumnya, namun jika segmentasi rambut seperti pada penelitian [19][20] terletak di area atas dan samping kepala, khimar terletak disekitar kepala hingga ke dada.

Modifikasi algoritme perlu dilakukan dengan mengkombinasikan Viola-Jones dan GMM dengan metode deteksi tepi Roberts, sehingga sistem dapat memberdakan antara khimar dengan tektur kulit. Manfaat penelitian ini adalah peringatan dini sistem deteksi aurat sehingga ke depan algoritme ini mampu berjalan secara real time.

\section{Metode Penelitian}

Secara umum metode penelitian yang dilaksanakan dalam penelitian ini terdiri dari beberapa proses seperti terlihat pada Gambar 1, mulai dari proses pra pengolahan yaitu pemotongan gambar area kepala hingga dada, kemudian deteksi area wajah, segmentasi kulit dan terakhir adalah klasifikasi. Proses klasifikasi menggunakan deteksi tepi untuk memeriksa apakah terdapat kulit yang belum menutupi aurat di area bawah dagu sampai leher.

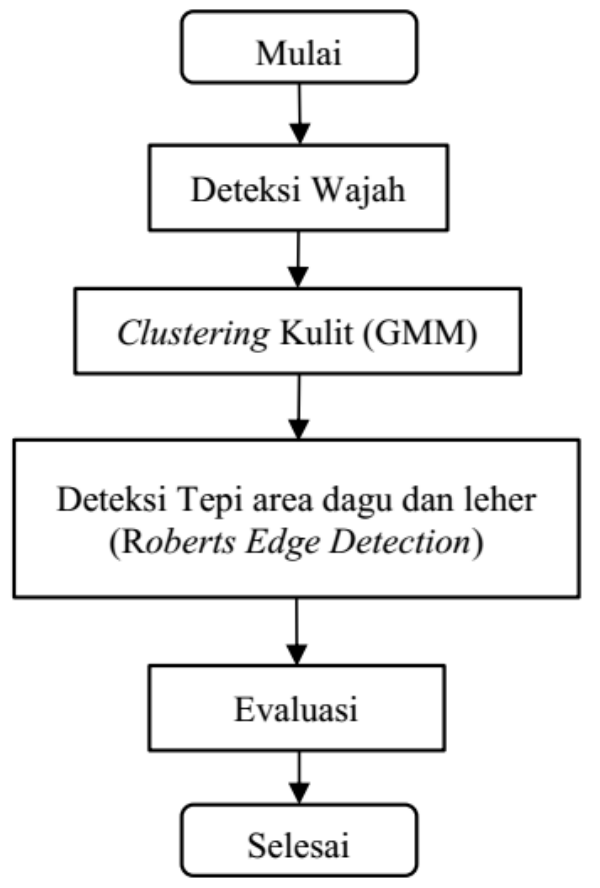

Gambar 1. Diagram alir penelitian

a. Face Detection

Proses deteksi wajah merupakan tahap yang bertujuan untuk memotong area wajah dan membuang bagian yang tidak diperlukan misalnya kaki, tangan, perut dan sebagainya. Tahapan ini terdiri dari dua proses yaitu pemotongan tubuh bagian atas dan pengenalan wajah. Pemotongan tubuh bagian atas bertujuan agar area pencarian wajah terhindar dari derau, contohnya penggunaan pakaian bermotif mata atau organ wajah lain yang akan mengganggu proses pengenalan wajah jika langsung dilakukan. Proses deteksi tubuh bagian atas dan deteksi wajah ini menjadi satu bagian terintegrasi pada algoritme Viola-Jones [21]. Pada dasarnya proses pengenalan wajah Viola-Jones [9] terdapat empat tahap berikut. 
1. Seleksi fitur Haar

2. Membuat integral gambar

3. Pelatihan Adaboost

4. Cascading Classifier

Konsep dari metode Viola-Jones yaitu berbasis fitur untuk proses klasifikasinya. Hal ini karena pemprosesan fitur lebih cepat dibandingkan dengan pemrosesan berbasis sliding neighborhood. Terdapat tiga buah fitur dalam metode ini seperti yang diperlihatkan pada Gambar 2.

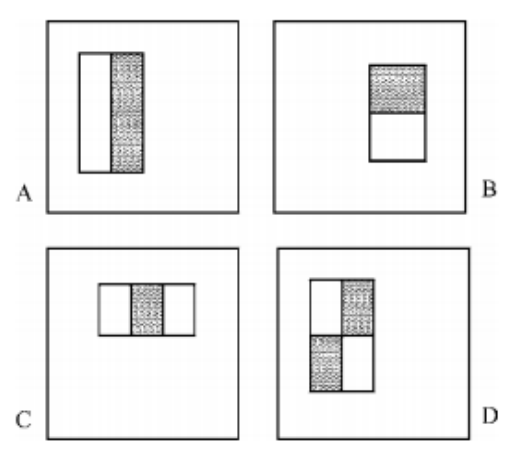

\section{Gambar 2. Jenis-jenis fitur citra}

Pada Gambar 2 mengilustrasikan bahwa fitur Haar diekstraksi dengan beberapa tipe gambar persegi panjang A, B, C dan D. Metode menghitung fitur gambar adalah dengan cara mencari selisih area piksel putih dengan area piksel hitam. Secara teoritis perhitungan nilai tersebut dapat direpresentasikan dengan menggunakan perhitungan integral image seperti dalam persamaan 1 .

$$
i i(x, y)=\sum_{x^{\prime} \leq x, y^{\prime} \leq y} i\left(x^{\prime}, y^{\prime}\right),
$$

Dimana $x$ dan $y$ adalah lokasi piksel, ii $(x, y)$ adalah integral image dan $i\left(x^{\prime}, y^{\prime}\right)$ adalah gambar asli. Selanjutnya ViolaJones menggunakan pendekatan Adaboost untuk memilih fitur yang spesifik. AdaBoost menggabungkan banyak classifier lemah untuk membuat sebuah classifier kuat. Lemah disini berarti urutan filter pada classifier hanya mendapatkan jawaban benar lebih sedikit. Jika keseluruhan classifier lemah digabungkan maka akan menjadi classifier yang lebih kuat [21]. Tahap selanjutnya yaitu dengan proses cascade. Pada proses cascade terjadi penentuan area wajah dan bukan wajah dengan cara menggunakan bobot yang diperoleh dari Adaboost.

Gambar 3(a) adalah citra asli sebagai input sistem. Data inputan kemudian dicrop otomatis menjadi seukuran area kepala dan bahu seperti pada Gambar 3(b). Selanjutnya dilakukan proses deteksi wajah beserta komponen-komponennya seperti mata, hidung dan mulut seperti yang diperlihatkan pada Gambar 3(c). Proses deteksi wajah ini dilakukan pada seluruh data sejumlah 20 data khimar dan 20 data non khimar. Proses pengenalan wajah ini nantinya digunakan untuk masukan selanjutnya pada algoritme segmentasi kulit.

Kulit merupakan area penting bagi sistem peringatan khimar ini. Kulit yang dimaksud adalah kulit wajah dan leher, dimana seseorang dikatakan mengenakan 
khimar jika kulit leher tertutupi oleh kain, sedangkan tidak mengenakan khimar jika area leher terdeteksi adanya kulit. Metode GMM diperlukan untuk mengelompokkan data kulit dan bukan kulit. Teknik ini menggunakan perhitungan statistik untuk melihat perbedaan fitur kulit dan bukan kulit. Metode GMM secara luas digunakan untuk mendeskripsikan distribusi warna [22].

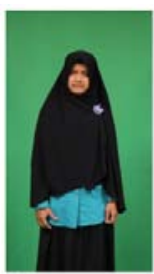

(a)

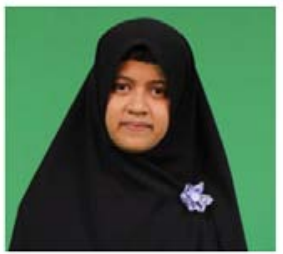

(b)

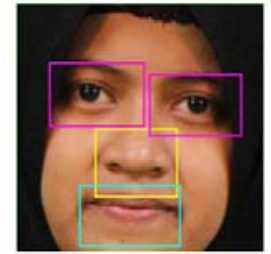

(c)
Gambar 3. Citra masukan (a), hasil crop kepala dan bahu (b), hasil deteksi wajah (c).

\section{b. Gaussian Mixture Model (GMM)} Algorithm

Pada tahap segmentasi kulit ini menggunakan metode GMM (Gaussian Mixture Model). GMM adalah model probabilitas berdasarkan distribusi Gaussian [23]. Mixture Model atau model campuran menjelaskan probabilitas distribusi keseluruhan dari populasi data. Dalam metode GMM, distribusi disini merupakan multivariat Gaussian. Multivariat merupakan kajian statistik yang mempelajari perilaku hubungan antara dua atau lebih variabel. GMM secara formal didefinisikan dalam persamaan 2.

$$
p(x \mid \alpha, M, S)=\sum_{i=1}^{n} \alpha_{i} * p\left(x \mid \mu_{i}, \Sigma_{i}\right)
$$

dimana $x$ adalah vektor pengamatan tertentu, $n$ adalah jumlah dari sub populasi, $\alpha$ adalah vektor proporsi campuran, $M$ adalah himpunan vektor rerata, $S$ adalah himpunan matriks kovarian, $i$ vektor rerata $\mu_{\mathrm{i}} \in M, i$ matriks kovarian $\Sigma_{\mathrm{i}} \in S$, dan $p\left(x \mid \mu_{\mathrm{i}}, \Sigma_{\mathrm{i}}\right)$ adalah PDF (Probability Density Function) dari distribusi Gaussian yang didefinisikan dalam persamaan 3 .

$$
p(x \mid \mu, \Sigma)=\frac{1}{(2 \pi)^{\frac{d}{2}} \operatorname{det}(\Sigma)^{\frac{1}{2}}} \exp \left(\frac{-1}{2}(x u)^{T} \Sigma^{-1}(x u)\right)
$$

dimana $x, \mu$ dan $\Sigma$ definisinya sama seperti dalam (2) dan $d$ adalah dimensi dari pengamatan vektor $x$. Metode GMM sering digunakan sebagai clustering. Pada tujuan ini, setiap cluster merepresentasikan suatu bagian populasi. Bagian populasi ini dijelaskan menggunakan vektor rerata $\mu$ dan matriks kovarian $\Sigma$. Tujuan dari proses clustering adalah memperkirakan parameter yang sesuai untuk setiap cluster. Pengamatan tertentu diberikan kepada cluster berdasarkan probabilitas yang telah dihasilkan dari distribusi yang direpresentasikan oleh cluster. Probabilitas setiap cluster ini dihitung menggunakan persamaan 4, dimana probabilitas setiap 
cluster dikalikan dengan vektor proporsi campuran hasil dari distribusi Gaussian.

$$
p(x \mid \alpha, \mu, \Sigma)=\alpha * p(x \mid \mu, \Sigma)
$$

\section{c. Expectation-Maximization (EM)}

Metode EM atau Expectation Maximization adalah suatu teknik yang bertujuan untuk mengestimasi parameter GMM berdasarkan fitur statistik. Algoritme EM dibagi menjadi 3 tahap, tahapan pertama adalah inisialisasi fase, dimana parameter $\mu$ diinisialisasi secara acak, atau menggunakan algoritme $k$ means, dan parameter yang lain yang dikumputasi berbasis pada $\mu$. Pada penelitian ini, peneliti menggunakan metode $k$-means. Berdasarkan penelitian [24] bahwa dengan menggunakan $k$-means proses inisialisasi parameter menjadi lebih baik. Tahap kedua, probabilitas keanggotaan cluster $(\tau)$ dikomputasi menggunakan persamaan 5 , metode ini disebut juga sebagai Tahap $E$.

$$
\tau_{i, \epsilon}=\alpha_{\epsilon} * p\left(x_{i} \mid \mu \mu_{\epsilon}, \Sigma_{\epsilon}\right)
$$

dimana $\alpha_{c}$ dan $p\left(x_{i} \mid \mu_{c}, \Sigma_{c}\right)$ seperti yang dijelaskan pada sesi sebelumnya, $i$ merupakan indeks pengamatan, dan $C$ adalah indeks cluster. Tahap ketiga disebut juga sebagai tahap $M$, parameter akan diperbaharui setiap perulangan cluster. Parameter $\alpha_{c}{ }^{\text {new }}$ diperbarui seperti dalam persamaan 6 .

$$
\alpha_{c}^{\text {new }}=\frac{\sum_{i=1}^{N} \tau_{i, e}}{\sum_{i=1}^{N} \sum_{j=1}^{C} \tau_{i, j}}
$$

dimana $N$ adalah jumlah pengamatan dan $C$ adalah jumlah cluster. Dua parameter sisanya yaitu $\mu_{c}^{\text {new }}$ dan $\Sigma_{c}^{\text {new }}$ diperbarui menggunakan persamaan 7 dan 8.

$$
\begin{aligned}
& \mu_{c}^{\text {new }}=\frac{\sum_{i=1}^{N} \tau_{i, \epsilon} x_{i}}{\sum_{i=1}^{N} \tau_{i, \epsilon}} \\
& \alpha_{c}^{\text {new }}=\frac{\sum_{i=1}^{N} \tau_{i, c}\left(x_{i}-\mu_{c}^{\text {new }}\right)\left(x_{i}-\mu_{c}^{\text {new }}\right)}{\sum_{i=1}^{N} \tau_{i, e}}
\end{aligned}
$$

Tahap kedua dan ketiga dari algoritme tersebut diiterasi hingga berhenti pada kriteria tertentu. Kriteria ini termasuk jumlah iterasi maksimum, atau maksimum log-likelihood [25], seperti dalam persamaan 9 .

$$
\max \sum_{i=1}^{c}=\log \sum_{j=1}^{N} \alpha_{c} * p\left(x_{i} \| \mu_{c}, \Sigma_{c}\right)
$$

\section{d. Skin Segmentation}

Proses segmentasi kulit Proses segmentasi kulit terdiri atas tahapan praproses segmentasi dan proses segmentasi menggunakan algoritme GMM dengan mengkombinasikan metode EM. Pada tahap pra-proses segmentasi akan diambil sampel kulit yang mewakili warna kulit 
citra orang yang bersangkutan. Proses pengambilan citra sampel kulit berdasarkan titik pusat dari citra wajah yang telah terdeteksi kemudian area citra sampel dihitung dengan menggunakan nilai perbandingan seperti pada persamaan 10 dan 11. Dimana $\Delta$ adalah tinggi area wajah, $x_{s}$ adalah kolom, $y_{s}$ adalah baris, sedangkan $\alpha=\beta=0.25$ adalah konstanta lebar dan tinggi area kulit wajah yang diambil. Ilustrasi pengambilan area leher tersebut diperlihatkan pada Gambar 4(a). Citra area dagu dan leher yang telah dicrop ditunjukkan pada Gambar 4(b).

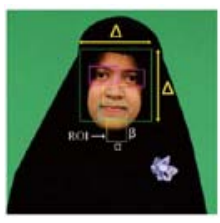

(a)

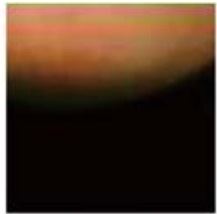

(b)

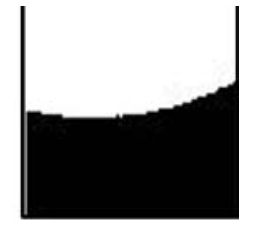

(c)
Gambar 4. Pengambilan area leher (a), citra area dagu dan leher (b), hasil komputasi GMM (c)

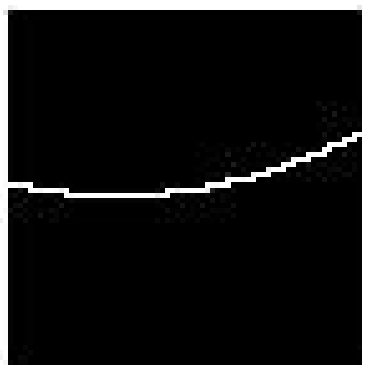

Gambar 5. Hasil segmentasi berbasis deteksi tepi

Proses segmentasi kulit dilakukan terhadap Gambar 4(b) dengan menggunakan metode GMM dan EM. Pada proses ini dilakukan clustering dengan nilai parameter $k=2$, yang berarti proses clustering dilakukan dengan membagi daerah menjadi dua kelas, yaitu daerah kulit (warna putih) dan daerah khimar (warna hitam) seperti tampak pada Gambar 4(c).

Penentuan klasifikasi seseorang mengenakan khimar atau tidak yaitu dengan menggunakan deteksi tepi. Deteksi tepi yang digunakan pada pengujian ini yaitu menggunakan algoritme Roberts. Seseorang mengenakan khimar apabila garis tepi melintang penuh dari kanan ke kiri. Namun seseorang tidak mengenakan khimar, tidak terdapat garis melintang penuh dari kanan ke kiri atau hanya berupa garis yang terputus seperti pada Gambar 5. Contoh hasil komputasi terhadap orang yang tidak mengenakan khimar ditunjukkan pada Gambar 6, dimana dari citra asli akan dicrop pada area leher, kemudian dilakukan GMM dan selanjutnya dilakukan operasi deteksi tepi untuk keperluan klasifikasinya.

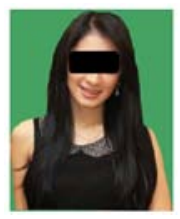

(a)

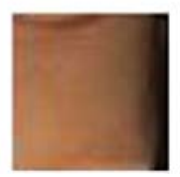

(b)

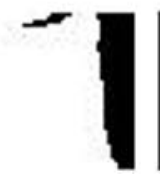

(c)

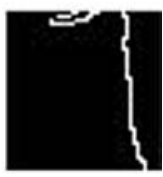

(d)
Gambar 6. Deteksi citra non-khimar.

(a) citra asli, (b) citra leher, (c) hasil sementasi leher, (d) hasil deteksi tepi (c) 
Pada penelitian ini, proses komputasi GMM dilakukan pada format grayscale karena fitur warna disini diabaikan dan diganti dengan fitur tekstur statistik. Klasifikasi penentuan khimar berdasarkan ada atau tidaknya garis yang melintang dari kiri hingga kanan citra hasil deteksi tepi. Jika terdapat garis lintang yang terputus, maka sistem akan mengenali seseorang tidak mengenakan khimar. Jika garis melintang secara penuh, maka sistem akan mengenali seseorang mengenakan khimar, seperti dijelaskan dalam persamaan 12.

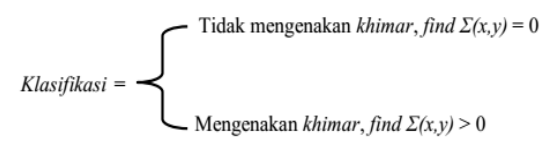

\section{HASIL DAN PEMbahasan}

Sebanyak 20 data wanita yang mengenakan khimar diakuisisi menggunakan kamera DSLR Canon EOS 700D beresolusi 18 Mega Piksel, format JPG dan dengan warna latar belakang seragam. Sedangkan sebanyak 20 data non-khimar juga diambil secara acak. Tabel 1 merupakan data hasil pengujian sistem beserta klasifikasi khimar. Evaluasi hasil klasifikasi penelitian diukur berdasarkan klasifikasi terbimbing, bahwa 20 data mengenakan khimar dan 20 data tidak mengenakan khimar. Dalam percobaan penelitian terhadap data khimar, terdapat satu kesalahan hasil pengenalan yaitu pada data 4, dimana pada data ini warna khimar yang dikenakan sangat mirip dengan warna kulit. Selain itu pada bagian segmentasi GMM terlihat bahwa intensitas gelap yang berada dibawah dagu dianggap sebagai cluster tersendiri. Sehingga pada saat dideteksi tepi garis tepi antara dagu dan khimar tidak jelas terlihat.

Tabel 1. Hasil Pengujian Terhadap Data Khimar

\begin{tabular}{|l|c|c|c|}
\hline \multirow{2}{*}{ No } & find & Hasil Sistem & Hasil \\
& $\boldsymbol{\Sigma}(\boldsymbol{x}, \boldsymbol{y})>\mathbf{0}$ & Memakai/Tidak & Evaluasi \\
\hline 1 & Ya & memakai & benar \\
\hline 2 & Ya & memakai & benar \\
\hline 3 & Ya & memakai & benar \\
\hline 4 & Tidak & tidak & salah \\
\hline 5 & Ya & memakai & benar \\
\hline 6 & Ya & memakai & benar \\
\hline 7 & Ya & memakai & benar \\
\hline 8 & Ya & memakai & benar \\
\hline 9 & Ya & memakai & benar \\
\hline 10 & Ya & memakai & benar \\
\hline 11 & Ya & memakai & benar \\
\hline 12 & Ya & memakai & benar \\
\hline 13 & Ya & memakai & benar \\
\hline 14 & Ya & memakai & benar \\
\hline 15 & Ya & memakai & benar \\
\hline 16 & Ya & memakai & benar \\
\hline 17 & Ya & memakai & benar \\
\hline 18 & Ya & memakai & benar \\
\hline 19 & Ya & memakai & benar \\
\hline 20 & Ya & memakai & benar \\
\hline & & & \\
\hline
\end{tabular}

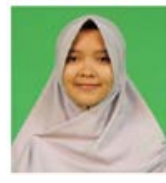

(a)

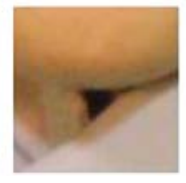

(b)

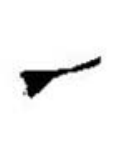

(c)

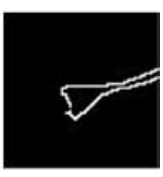

(d)
Gambar 7. Kesalahan deteksi. citra asli (a), citra leher (b), hasil sementasi leher (c), hasil deteksi tepi (d) 
Tabel 1 menunjukkan hasil percobaan terhadap data khimar. Keluaran yang seharusnya dari sistem adalah apabila terdapat kondisi find $\Sigma(\mathrm{x}, \mathrm{y})>0$, yang berarti ditemukan garis melintang dari kiri hingga kanan, seperti yang diperihatkan pada Gambar. 6(d). Terdapat satu kesalahan yaitu data keempat yang diperlihatkan pada Gambar 7. Berdasarkan percobaan ini, nilai akurasi yang dicapai adalah 95\%.

Tabel 2. Hasil Pengujian Terhadap Data Non-Khimar

\begin{tabular}{|l|c|c|c|}
\hline \multirow{2}{*}{ No } & find & Hasil Sistem & Hasil \\
& $\boldsymbol{\Sigma}(\boldsymbol{x}, \boldsymbol{y})=\mathbf{0}$ & Memakai/Tidak & Evaluasi \\
\hline 1 & ya & tidak & benar \\
\hline 2 & ya & tidak & benar \\
\hline 3 & ya & tidak & benar \\
\hline 4 & ya & tidak & benar \\
\hline 5 & ya & tidak & benar \\
\hline 6 & ya & tidak & benar \\
\hline 7 & ya & tidak & benar \\
\hline 8 & ya & tidak & benar \\
\hline 9 & ya & tidak & benar \\
\hline 10 & ya & tidak & benar \\
\hline 11 & ya & tidak & benar \\
\hline 12 & ya & tidak & benar \\
\hline 13 & ya & tidak & benar \\
\hline 14 & ya & tidak & benar \\
\hline 15 & ya & tidak & benar \\
\hline 16 & ya & tidak & benar \\
\hline 17 & ya & tidak & benar \\
\hline 18 & ya & tidak & benar \\
\hline 19 & ya & tidak & benar \\
\hline 20 & ya & tidak & benar \\
\hline
\end{tabular}

Berdasarkan Tabel 2, pengujian juga telah dilakukan menggunakan 20 data wanita non-khimar yang diambil secara acak, seperti yang ditunjukkan pada Gambar 6. Hasil memperlihatkan bahwa tingkat akurasi sistem mencapai 100\%, dimana seluruh data berhasil dikenali dengan tepat. Seluruh citra memenuhi kondisi find $\Sigma(\mathrm{x}, \mathrm{y})=0$, yang artinya terdapat garis lintang yang terputus seperti yang diperlihatkan Gambar 6(d) dan Gambar 7(d).

\section{SimpUlan}

Khimar merupakan pakaian wajib bagi kaum muslimah yang berfungsi untuk meutupi aurat bagian kepala. Berbagai dampak buruk dapat terjadi bagi kaum muslimah yang belum mengenakan khimar syar'iah seperti kekerasan terhadap wanita. Ditambah lagi dengan perkembangan media sosial yang semakin luas, potensi kejahatan kaum laki-laki terhadap perempuan pun semakin bertambah. Solusi untuk mengatasi hal tersebut adalah dengan filterisasi aurat wanita berbasis computer vision, misalnya dengan melakukan seleksi foto muslimah di situs-situs yang dianggap penting bagi umat islam yang masih terlihat aurat wajahnya karena belum mengenakan khimar.

Deteksi aurat berbasis segmentasi kulit dapat dilakukan untuk mengatasi hal ini. Berdasarkan hasil pengujian sistem ini, diperoleh hasil akurasi 95\%. Pada kondisi dimana warna kulit sama dengan warna khimar, sistem berpeluang mengalami kesalahan, karena nilai distribusi gaussian 
kulit sama dengan warna khimar. Namun untuk hasil pengujian sistem terhadap 20 data wanita non-khimar, akurasi sistem mencapai $100 \%$. Berdasarkan percobaan tersebut, seluruh data uji non-khimar dapat dikenali dengan baik. Seluruh pengujian dilakukan dengan citra wajah menghadap ke depan (frontal).

\section{PENELITIAN LANJUTAN}

Untuk penelitian selanjutnya dibutuhkan pengenalan fitur lain sebagai pembeda antara kulit dengan khimar, seperti rambut, tekstur kulit dan lain sebagainya, sehingga sistem memungkinkan untuk melakukan deteksi khimar dengan berbagai posisi atau sudut pengambilan foto.

\section{DAFTAR PUSTAKA}

[1] R. Sihite, 2013, "Kekerasan Negara Terhadap Perempuan,” $J$. Kriminologi Indones. I Juli, vol. 3, no. I, pp. 33-42.

[2] Klette, R., 2014, Concise Computer Vision 1st ed. London: SpringerVerlag London.

[3] Tim Morris, 2004, Computer Vision and Image Processing. Britania: Palgrave Macmillan.

[4] Sonka, M., Hlavac, V., dan R. Boyle, 2008, Image Processing, Analysis, and Machine Vision. Boston: Spinger.

[5] Forsyth, D. A. dan Ponce, J., 2003, Computer Vision, A Modern Approach. New Jersey: Prentice Hall International.

[6] Alzubaydi, D. A. dan Yousif, S. A., 2014, “Face Clip Detection System
Using HSV Color Model”, Int. J. Innov. Res. Adv. Eng., vol. 1, no. 11.

[7] Bhat. S. Vandana dan Pujari, J. D., 2013 "Face Detection System Using HSV Color Model and Morphing Operations”, Int. J. Curr. Eng. Technol.

[8] Saikia, P., Janam, G., dan Kathing, M.,2012, "Face Dection using Skin Colour Model and distance between Eyes”, Int. J. Comput. Commun. Netw., vol. 1 No.3, 2012.

[9] Viola, P. dan Jones, M. J., 2004, "Robust Real-Time Face Detection”, Int. J. Comput. Vis., vol. 57, no. 2, pp. 137-154.

[10] Randive, H. B. Mali, dan Lokhande, S. D., 2012, "Hand Gesture Segmentation”, Int. J. Comput. Technol. Electron. Eng., vol. 2, no. 3.

[11] Duong, L., Cheriet, F., dan Labelle, H., 2010, "Automatic detection of scoliotic curves in posteroanterior radiographs", IEEE Trans. Biomed. Eng., vol. 57, no. 5, pp. 1143-51.

[12] Zhang, Q., Zhang, J. Lu, M, Duan, H., dan Lai, F., 2015, "Hand Gesture Segmentation Based on Mixed Skin-Color Model and FCM Algorithm”, J. Inf. Comput. Sci., vol. 12, no. 9, 2015.

[13] Dongare, Y. B. dan Patole, R., 2015, "Skin Color Detection And Background Subtraction Fusion For Hand Gesture Segmentation”, Int. J. Eng. Res. Gen. Sci., vol. 3, no. 4.

[14] Mehdi, H. dan Mureed, H., 2013, "A survey of image steganography techniques", Int. J. Adv. Sci. Technol., vol. 54, no. 3, pp. 113124.

[15] Hussain, S. A. K., 2015, "Human Face Detection with skin color properties”, Int. J. Sci. Eng. Res., vol. 6, no. 6 .

[16] Chaudhari, M. dan Vanjare, G., 2015, “A review on Face Detection 
and study of Viola Jones method”, International Journal of Computer Trends and Technology, vol. 25, no. 1, pp. 54-61.

[17] Yang, M. dan Ahuja, N., 1998, "Gaussian Mixture Model for Human Skin Color and Its Applications in Image and Video Databases", Proc. SPIE 3656, Storage and Retrieval for Image and Video Databases VII, p. 458.

[18] Zhang, J., Hong, X., Guan, S., Zhao, X., Huang, X., dan Xue, N., 2016, "Maximum Gaussian Mixture Model for Classification”, International Conference on Information Technology in Medicine and Education, p. 587.

[19] Yacoob, Y. dan Davis, L. S., 2006, "Detection and Analysis of Hair", IEEE Trans. Patterng Anal. Mach. Intell., vol. 28 No.7.

[20] Shen, Y., Peng, Z., dan Zhang, Y., 2015, "Image Based Hair Segmentation Algorithm for the Application of Automatic Facial Caricature Synthesis”, Sci. World J., vol. 2014.

[21] Putro, M. D., Adji, T. B., dan Winduratna, B., 2012, "Sistem Deteksi Wajah dengan Menggunakan Metode ViolaJones", Science, Engineering and Technology (SciETec).

[22] Wang, J., Ying, Y., Guo, Y., dan Peng, Q., 2006, “Automatic Foreground Extraction of Head Shoulder Images”, Computer Graphics International Conference, pp. 385-396.

[23] Janoǔ, J., Gajdo , P., dan Radeck, M., 2015, "Gaussian Mixture Model Cluster Forest", International Conference on Machine Learning and Applications, pp. 1019-1023.

[24] Bl, J. dan Bujna, K., 2016,"Simple Methods for Initializing the EM Algorithm for Gaussian Mixture
Models”, 20th Pfici Asia Conference on Knowledge Discovery and Data Mining (PAKDD).

[25] Edwards, A. W. F., 1992, Likelihood, Baltimore: Johns Hopkins University Press. 